\title{
Los orígenes de la Cartilla Nacional de Vacunación
}

\section{The origins of the National Vaccination Card}

La Cartilla Nacional de Vacunación se instituyó en la República Mexicana por Decreto Presidencial, publicado en el Diario Oficial de la Federación, el día 20 de octubre de 1978. Entró en vigor el día $1^{\circ}$ de enero de 1979 . Su propósito original fue apoyar al Sistema Nacional de Salud en el registro de las acciones de vacunación a menores de cinco años.

Desde aquel entonces, la Cartilla ha sido una herramienta básica con amplio posicionamiento en la población y es considerada un elemento relevante entre toda la documentación necesaria para certificar a los niños de México.

El concepto rector de la cartilla surgió en la Dirección General de Epidemiología y Campañas Sanitarias de la entonces Secretaría de Salubridad y Asistencia, por histórica iniciativa de su titular, el Médico Pediatra y Maestro en Salud Pública, Alfredo Heredia Duarte, quien desde tiempo antes había sostenido públicamente la necesidad ingente de tal documento.

Alfredo Heredia Duarte se formó como pediatra en el Hospital Infantil de México (egresado en 1956) que ahora lleva el nombre de su ilustre fundador, el Dr. Federico Gómez. En el curso de años previos realizó actividades de índole sociomédica y de naturaleza variada principalmente en Michoacán, su estado natal. Ya como pedíatra ingresó a la entonces denominada Escuela de
Salubridad, de la cual se graduó como Maestro en Salud Pública en 1957.

Veinte años más tarde, como director de la citada dependencia, el doctor Heredia logró que su proposición para instrumentar un documento único y de vigencia permanente cobrara fuerza, y que éste sirviera como constancia y orientador del obligado proceso de vacunación. Contando con el parecer de las principales agrupaciones pediátricas del país y con la asesoría de expertos nacionales y extranjeros, pronto quedó conformado el planteamiento original. En acatamiento de los preceptos y dictados de la disciplina de salud, el proyecto fue sometido a una rigurosa prueba de campo. La entidad elegida para tal propósito fue Aguascalientes, por sus características geográficas y poblacionales.

El estudio piloto quedó a cargo del médico pediatra Ismael Landin Miranda, Jefe de los Servicios Coordinados de Salud de Estado de Aguascalientes. El doctor Landin había egresado en 1974 del Hospital de Pediatría del primer Centro Médico Nacional del Instituto Mexicano del Seguro Social, unidad médica de alta especialidad, que ahora lleva el nombre del doctor Silvestre Frenk.

El Estado de Aguascalientes resultó ser ideal para instrumentar dicha prueba de campo, por su relativamente pequeña extensión territorial, 
por hallarse bien comunicado, con una elevada tasa de población urbana altamente alfabetizada y con aceptable proporción de asistencia escolar. El Consejo Estatal de Salud, asistido por expertos nacionales e internacionales en materia de inmunizaciones, aprobó la instrumentación del carnet único de vacunación, previo un acuerdo favorable interinstitucional.

La implantación oficial de la Cartilla ocurrió rápidamente. Desde entonces, constituye un efectivo y óptimo instrumento de apoyo al Sistema Nacional de Salud en el registro de todas las acciones oficiales de vacunación y motivo adicional de su aceptación dentro de la población.

Hoy día, una inmensa mayoría de las madres la consideran como identificación de sus hijos. Durante casi veinte años, la cartilla registró la aplicación sistemática del esquema internacional de inmunizaciones; además, desde 1996 se le agregaron tablas de los valores reconocidos de peso y talla, como instrumento de valoración oportuna de la condición nutricional de los niños vacunados. A partir de 1998 se ha prolongado su marco cronológico hasta la edad de 19 años y, por el cambiante panorama epidemiológico del país, se han incorporado vacunas requeridas, gracias a las que han quedado virtualmente erradicados la mayoría de los azotes infecciosos que antes afectaban a nuestra niñez $y$, consecuentemente, robustecida la calidad de vida de los mexicanos.

Puede decirse que los esfuerzos del doctor Alfredo Heredia Duarte y la gestación de sus ideas para mejorar la salud de los mexicanos fueron extremadamente útiles. A lo largo de los años se ha logrado poner en práctica la medicina preventiva y curativa, gracias a lo cual nuestro país puede salir de su subdesarrollo con voluntad política y con decisiones acertadas del Sistema de Salud de México.

Judith Vázquez-Santaella Médica cirujana, hematóloga pediatra 